\title{
Characterization of the inflammatory cells in ascending thoracic aortic aneurysms in patients with Marfan syndrome, familial thoracic aortic aneurysms, and sporadic aneurysms
}

\author{
Rumin He, MD, ${ }^{a}$ ** Dong-Chuan Guo, PhD, ${ }^{a}, *$ Wei Sun, PhD, ${ }^{d}$ Christina L. Papke, BS, ${ }^{a}$ Senthil Duraisamy, PhD, \\ Anthony L. Estrera, MD, ${ }^{\mathrm{b}}$ Hazim J. Safi, MD, ${ }^{\mathrm{b}}$ Chul Ahn, PhD, ${ }^{\mathrm{a}}$ L. Maximilian Buja, MD, ${ }^{\mathrm{c}}$ Frank C. Arnett, MD, \\ Jingwu Zhang, MD, ${ }^{d}$ Yong-Jian Geng, MD, PhD, and Dianna M. Milewicz, MD, PhD ${ }^{a}$
}

丹 Supplemental material is available online.
From the Departments of Internal Medicine, Cardiovascular Surgery, ${ }^{\mathrm{b}}$ and Pathology, The University of Texas Medical School at Houston, Texas; and Department of Immunology, Baylor College of Medicine, ${ }^{\mathrm{d}}$ Houston, Texas.

This work was supported by the National Institutes of Health R01HL62594 and P50HL083794 (D. M. M.), R01HL59249 and RO1HL69509 (Y. J. G.), the Doris Duke Foundation (D. M. M), and General Clinical Research Center (MO1RR02558).

* Drs $\mathrm{He}$ and Guo contributed equally to this work.

Received for publication June 30, 2007; revisions received Nov 28, 2007; accepted for publication Dec 18, 2007.

Address for reprints: Dianna M. Milewicz, $\mathrm{MD}, \mathrm{PhD}$, The University of Texas Medical School at Houston, 6431 Fanin St, MSB 6.100, Houston, TX 77030 (E-mail: Dianna.M.Milewicz@uth.tmc.edu).

J Thorac Cardiovasc Surg 2008;136:922-9 $0022-5223 / \$ 34.00$

Copyright $(\subset) 2008$ by The American Association for Thoracic Surgery

doi:10.1016/j.jtcvs.2007.12.063
Objective: This study sought to characterize the inflammatory infiltrate in ascending thoracic aortic aneurysm in patients with Marfan syndrome, familial thoracic aortic aneurysm, or nonfamilial thoracic aortic aneurysm.

Background: Thoracic aortic aneurysms are associated with a pathologic lesion termed "medial degeneration," which is described as a noninflammatory lesion. Thoracic aortic aneurysms are a complication of Marfan syndrome and can be inherited in an autosomal dominant manner of familial thoracic aortic aneurysm.

Methods: Full aortic segments were collected from patients undergoing elective repair with Marfan syndrome $(n=5)$, familial thoracic aortic aneurysm $(n=6)$, and thoracic aortic aneurysms $(n=9)$, along with control aortas $(n=5)$. Immunohistochemistry staining was performed using antibodies directed against markers of lymphocytes and macrophages. Real-time polymerase chain reaction analysis was performed to quantify the expression level of the T-cell receptor $\beta$-chain variable region gene.

Results: Immunohistochemistry of thoracic aortic aneurysm aortas demonstrated that the media and adventitia from Marfan syndrome, familial thoracic aortic aneurysm, and sporadic cases had increased numbers of $\mathrm{T}$ lymphocytes and macrophages when compared with control aortas. The number of $\mathrm{T}$ cells and macrophages in the aortic media of the aneurysm correlated inversely with the patient's age at the time of prophylactic surgical repair of the aorta. T-cell receptor profiling indicated a similar clonal nature of the $\mathrm{T}$ cells in the aortic wall in a majority of aneurysms, whether the patient had Marfan syndrome, familial thoracic aortic aneurysm, or sporadic disease.

Conclusion: These results indicate that the infiltration of inflammatory cells contributes to the pathogenesis of thoracic aortic aneurysms. Superantigen-driven stimulation of $\mathrm{T}$ lymphocytes in the aortic tissues of patients with thoracic aortic aneurysms may contribute to the initial immune response.

A ortic aneurysms are classified in terms of their anatomic location and most commonly occur in the infrarenal abdominal aorta (abdominal aortic aneurysm [AAA]) and thoracic aorta (thoracic aortic aneurysm [TAA]). AAAs primarily affect the elderly population and are characterized by atherosclerotic changes with chronic inflammation of the aortic wall. In contrast, TAAs affect a younger population and the pathology present in the aortic wall in these patients is medial degeneration (MD), described as a lesion characterized by the triad of loss of smooth muscle cells, fragmented and diminished number of elastic fibers, and increased accumulation of proteoglycans. ${ }^{1}$ Individuals with TAAs are referred for prophylactic 


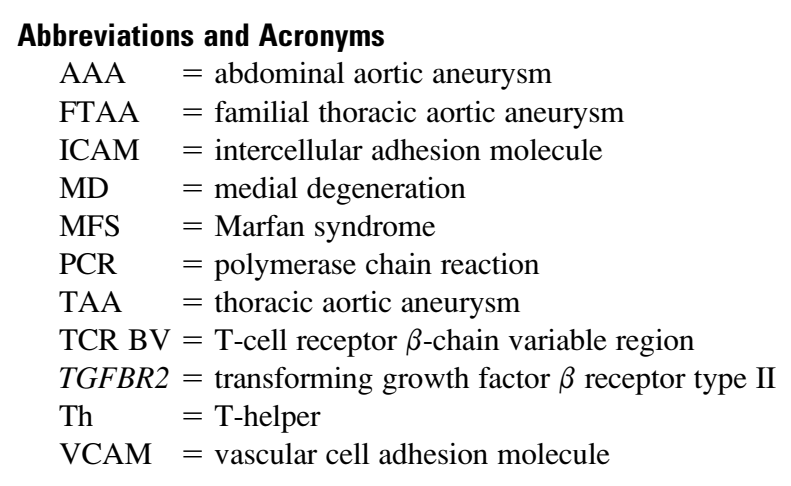

surgical repair of the ascending aorta when an aneurysm reaches a diameter greater than $5 \mathrm{~cm}$ to prevent the life-threatening complications of aortic dissection or rupture. ${ }^{2}$

A number of genetic conditions can predispose individuals to the formation of TAAs, most notably Marfan syndrome (MFS). ${ }^{3}$ MFS is a pleiotropic condition inherited in an autosomal dominant manner that has associated skeletal and ocular manifestations. A defective gene causing MFS, $F B N 1$, encodes for an extracellular matrix protein called "fibrillin-1," a component of the elastic fiber system. The fibrillin-1 deficient mouse, an accepted model of MFS that recapitulates the cardiovascular phenotype, shows MD in the aortic wall that is associated with inflammatory infiltrates before dilatation or dissection. ${ }^{4}$ A second gene for MFS was recently identified as transforming growth factor $\beta$ receptor type II (TGFBR2). ${ }^{5}$

A genetic predisposition for TAA can also be inherited in an autosomal dominant manner in the absence of any associated syndromic findings. Families with multiple affected members typically demonstrate autosomal dominant inheritance with decreased penetrance and variable expression, indicating that a single defective gene is responsible for the disease. ${ }^{6,7}$ Genetic heterogeneity has been demonstrated for familial TAA, and 4 chromosomal loci have been mapped for inherited forms of thoracic aortic disease: TAADl on $5 \mathrm{q},{ }^{8}$ TAAD2 on $3 \mathrm{p},{ }^{9}$ TAAD4 on $10 \mathrm{q},{ }^{10}$ the FAAl locus on $11 \mathrm{q},{ }^{11}$ and a locus of $16 \mathrm{p}$ for TAA associated with patent ductus arteriosus. ${ }^{12}$ The defective gene at the TAAD2 locus was recently identified as TGFBR2. Mutations in TGFBR2, TGFBR1, ACTA2, and MYH11 have been identified that lead to varied phenotypes associated with TAAs and dissections. ${ }^{5,13,14}$ Similar to MFS, the aortas of patients with familial forms of TAA also demonstrate MD.

Previous studies have documented an inflammatory infiltrate in the aortic wall of patients with TAA. ${ }^{15,16}$ In aortas of patients undergoing prophylactic repair of TAAs, there were significant increases in the number of CD3+ and CD68+ cells throughout the aortic media and adventitia when compared with control aortas. ${ }^{15}$ Other investigators have also documented an inflammatory infiltrate in the aortic wall that was associated with interferon-gamma production production. ${ }^{16}$ In this study, we sought to further characterize the inflammatory infiltrate in aortas of patients referred for prophylactic repair of an ascending aortic aneurysm resulting from single gene defects, such as MFS and familial TAA, and sporadic, nonfamilial cases.

\section{Materials and Methods \\ Subjects and Collection of Tissues}

All patients gave signed consent to these studies, which were approved by the Institutional Review Board at the University of Texas Health Science Center at Houston. Full aortic segments were collected from patients undergoing elective repair of TAAs $(\mathrm{N}=20$; 12 male and 8 female, mean age $46.9 \pm 16.6$ years, range, $21-77$ years) (Table 1). Five patients had MFS (3 male and 2 female, mean age $35.6 \pm 11.2$ years, range, $25-49$ years), 6 unrelated patients had a family history of TAAs ( 4 male and 2 female, mean age $44.8 \pm 18.1$ years, range, $21-67$ years), and 9 patients had sporadic TAA ( 5 male and 4 female, mean age $54.6 \pm 15.4$ years, range, 39-77 years). Control ascending aortas were obtained from 5 individuals at autopsy who died of a cause unrelated to aortic disease and were not septic at the time of death (2 male and 3 female, mean age $57.2 \pm 12.5$ years, range, $44-74$ years). Aortic specimens were immediately transferred to the laboratory in a container with cold Waymouth's MB 752/1 Medium (Invitrogen Corp, Carlsbad, Calif). Each specimen was divided into several parts for histochemistry, protein, and RNA extraction.

\section{Immunohistochemistry Analysis of Aortic Tissue}

The same antibodies were used for immunohistochemistry assay as the previous study. ${ }^{15}$ The antibodies reacting to intercellular adhesion molecule (ICAM)-1, vascular cell adhesion molecule (VCAM)-1, and S-100 were obtained from Dako (Carpinteria, Calif), and the antibody to CD83 was obtained from Santa Cruz Biotechnology (Santa Cruz, Calif). Immunohistochemistry assay followed a standard protocol. ${ }^{15}$

\section{T-cell Receptor $\beta$-Chain Variable Region Gene Expression by Real-time Polymerase Chain Reaction Analysis}

Total RNA was extracted from aortic tissue and peripheral blood mononuclear cells using the RNeasy Mini kit (Qiagen Valencia, Calif). cDNA was synthesized with Superscript II Reverse Transcriptase (Invitrogen, Carlsbad, Calif). T-cell receptor $\beta$-chain variable region (TCR BV) and TCR BJ gene expression was analyzed by real-time quantitative polymerase chain reaction (PCR). Real-time PCR was performed in 96-well optical PCR plates with SYBR-Green PCR Master Mix (Applied Biosystems, Foster City, Calif) on an ABI 7000 Sequence Detection System (Applied Biosystems) following published protocols. ${ }^{17,18}$ Reactions were performed in duplicate.

\section{Statistics Analysis}

To test whether there were significant differences in the number of positive inflammatory cell staining in the aortas between controls and patients with MFS, familial thoracic aortic aneurysm (FTAA), and TAA, exact Wilcoxon rank-sum tests were performed. Multiple 
TABLE 1. Clinical information of study participants

\begin{tabular}{|c|c|c|c|c|c|c|c|c|c|c|c|c|c|}
\hline Sample ID & $\mathrm{TCR}^{\mathrm{a}}$ & $\begin{array}{c}\text { Age } \\
\text { correlation }^{\mathrm{a}}\end{array}$ & Cell count ${ }^{\mathrm{a}}$ & Cause & Ethnicity & Gender & $\begin{array}{l}\text { Age at } \\
\text { surgery }\end{array}$ & $\begin{array}{c}\text { Diameter } \\
\text { of aorta }\end{array}$ & Smoking & HTN & BAV & $\mathrm{CD}^{3+}$ & $C D^{68+}$ \\
\hline 2664 & & & $Y$ & Control & $C$ & $\mathrm{~F}$ & 48 & Normal & NA & NA & $\mathrm{N}$ & $0.9^{b}$ & $0.9^{b}$ \\
\hline 2840 & $Y$ & & $Y$ & Control & B & $\mathrm{F}$ & 74 & Normal & NA & NA & $\mathrm{N}$ & 0.9 & 0.9 \\
\hline 2613 & $Y$ & & $Y$ & Control & B & $M$ & 44 & Normal & NA & NA & $\mathrm{N}$ & 1.4 & 0.9 \\
\hline 2701 & $Y$ & & $Y$ & Control & $\mathrm{H}$ & $\mathrm{F}$ & 54 & Normal & NA & NA & $\mathrm{N}$ & 0.5 & 0.0 \\
\hline 2976 & $Y$ & & $Y$ & Control & $\mathrm{H}$ & $M$ & 66 & Normal & NA & NA & $\mathrm{N}$ & 3.2 & 0.9 \\
\hline 2819 & $Y$ & $Y$ & $Y$ & MFS & $\mathrm{H}$ & $F$ & 46 & 5.2 & $\mathrm{~N}$ & $Y$ & $\mathrm{~N}$ & 52.7 & 23.2 \\
\hline 3035 & $Y$ & $Y$ & $Y$ & MFS & $\mathrm{H}$ & $M$ & 26 & 5.8 & $\mathrm{~N}$ & $\mathrm{~N}$ & $\mathrm{~N}$ & 93.6 & 20.0 \\
\hline 4520 & $Y$ & $Y$ & $Y$ & MFS & C & $\mathrm{M}$ & 25 & 5.2 & $\mathrm{~N}$ & $\mathrm{~N}$ & $\mathrm{~N}$ & 51.8 & 23.6 \\
\hline 4931 & $Y$ & $Y$ & $Y$ & MFS & B & $\mathrm{F}$ & 49 & 6.0 & $Y$ & $Y$ & $\mathrm{~N}$ & 115.9 & 16.8 \\
\hline 4958 & $Y$ & $Y$ & $Y$ & MFS & B & $M$ & 32 & 6.0 & $Y$ & $Y$ & $\mathrm{~N}$ & 58.6 & 26.4 \\
\hline 846 & $Y$ & $Y$ & $Y$ & FTAA & C & $M$ & 67 & $\mathrm{~N} / \mathrm{A}$ & $Y$ & $Y$ & $\mathrm{~N}$ & 61.8 & 13.6 \\
\hline 4047 & $Y$ & $Y$ & $Y$ & FTAA & C & $M$ & 56 & 5.7 & $\mathrm{~N}$ & $Y$ & $Y$ & 35.0 & 18.2 \\
\hline 5010 & $Y$ & & & FTAA & C & $\mathrm{F}$ & 55 & 6.7 & $\mathrm{~N}$ & $\mathrm{~N}$ & $\mathrm{~N}$ & 56.8 & 35.2 \\
\hline 2785 & $Y$ & $Y$ & $Y$ & FTAA & C & $M$ & 21 & 4.5 & $Y$ & $\mathrm{~N}$ & $\mathrm{~N}$ & 60.9 & 41.4 \\
\hline 3400 & $Y$ & $Y$ & $Y$ & FTAA & C & $M$ & 26 & 5.5 & NA & $\mathrm{N}$ & NA & 38.2 & 22.3 \\
\hline 4477 & & $Y$ & $Y$ & FTAA & C & $\mathrm{F}$ & 44 & 4.9 & $\mathrm{~N}$ & $\mathrm{~N}$ & $\mathrm{~N}$ & 61.8 & 30.9 \\
\hline 3943 & $Y$ & $Y$ & $Y$ & TAA & C & $M$ & 42 & 6.3 & $\mathrm{~N}$ & $\mathrm{~N}$ & $\mathrm{~N}$ & 42.3 & 9.1 \\
\hline 4718 & $Y$ & $Y$ & $Y$ & TAA & C & $\mathrm{M}$ & 39 & 4.6 & $\mathrm{~N}$ & $Y$ & $Y$ & 50.9 & 10.0 \\
\hline 4488 & $Y$ & $Y$ & $Y$ & TAA & C & $M$ & 52 & 4.7 & $\mathrm{~N}$ & $\mathrm{~N}$ & $\mathrm{~N}$ & 22.7 & 9.1 \\
\hline 4683 & $Y$ & $Y$ & $Y$ & TAA & C & $\mathrm{F}$ & 44 & 5.0 & $Y$ & $\mathrm{~N}$ & $Y$ & 3.6 & 0 \\
\hline 2478 & & $Y$ & $Y$ & TAA & C & $\mathrm{F}$ & 74 & 5.9 & $Y$ & $Y$ & $\mathrm{~N}$ & 7.7 & 6.8 \\
\hline 2496 & & $Y$ & $Y$ & TAA & C & $\mathrm{F}$ & 77 & 5.7 & $\mathrm{~N}$ & $Y$ & $\mathrm{~N}$ & 4.5 & 6.4 \\
\hline 2945 & & $Y$ & $Y$ & TAA & C & $\mathrm{F}$ & 40 & 6.0 & $\mathrm{~N}$ & $Y$ & $\mathrm{~N}$ & 53.6 & 9.5 \\
\hline 2955 & & $Y$ & $Y$ & TAA & C & $M$ & 52 & 5.2 & $\mathrm{~N}$ & $Y$ & $\mathrm{~N}$ & 29.5 & 7.3 \\
\hline 3393 & & $Y$ & $Y$ & TAA & C & $M$ & 71 & 5.6 & $Y$ & $Y$ & NA & 20.5 & 6.8 \\
\hline
\end{tabular}

MFS, Marfan syndrome; FTAA, familial thoracic aortic aneurysm; TAA, thoracic aortic aneurysm; HTN, hypertension; $B A V$, bicuspid aortic valve; NA, not available. ${ }^{\text {a }} Y=$ means that this samples has been used for the T-cell receptor assay, counting the number of various inflammatory cells present in the aortic media, the correlation assay of the number of T lymphocytes and macrophages present in the aortic media, and the patient's age at the time of prophylactic repair.

${ }^{\mathrm{b}}$ Total cells per square millimeter.

comparison corrections were made using Bonferroni corrections (significance levels were corrected for multiple comparisons by dividing them by the number of multiple comparisons). Linear regression analyses were conducted to investigate the association between the number of positive cells and the age at surgery.

\section{Results}

Characterization of the Inflammatory Cells in

Thoracic Aortic Aneurysms of Patients with Marfan Syndrome, Familial Thoracic Aortic Aneurysm, and Sporadic Thoracic Aortic Aneurysm Referred for Prophylactic Surgical Repair

Immunohistochemistry was performed using monoclonal antibodies directed against markers for $\mathrm{T}$ and $\mathrm{B}$ lymphocytes and macrophages to characterize the cells present in the aneurysm wall in patients undergoing prophylactic repair of an ascending aortic aneurysm. CD3 $+\mathrm{T}$ cells were clearly observed throughout the sections of aortic media and adventitia of all patients with aneurysms but not in the control aortas (Figure 1, CD3 staining), and confirmed by immunostaining with a monoclonal antibody to CD45 (data not shown). Further characterization indicated that $\mathrm{CD} 4+$ and $\mathrm{CD} 8+\mathrm{T}$ cells were both present in the aortas (Figure 1, CD4 and CD8 staining). CD20 immunostaining detected a few B lymphocytes in the TAAs but no cells in control aortas (Figure 1, CD20 staining). Staining with macrophage-specific antibody indicated that all aneurysm tissue sections contained CD68+ macrophages that were frequently present diffusely in the

Figure 1. Immunohistochemistry for markers of immune cells in the media and adventitia of aortas from controls and patients with MFS, FTAA, and TAA. The marker recognized by the antibody used for immunohistochemistry, the segment of the aorta photographed, and the magnification are on the left. The cause of the aneurysm is on the top. The orientation in the photographs is the lumen of the aorta at the bottom and the adventitia at the top. Color was developed with DAB for peroxidase (brown) or Fast Red for alkaline phosphatase (red). Magnification $200 \times$ for panels except CD3 adventitia staining. MFS, Marfan syndrome; FTAA, familial thoracic aortic aneurysm; TAA, thoracic aortic aneurysm. 


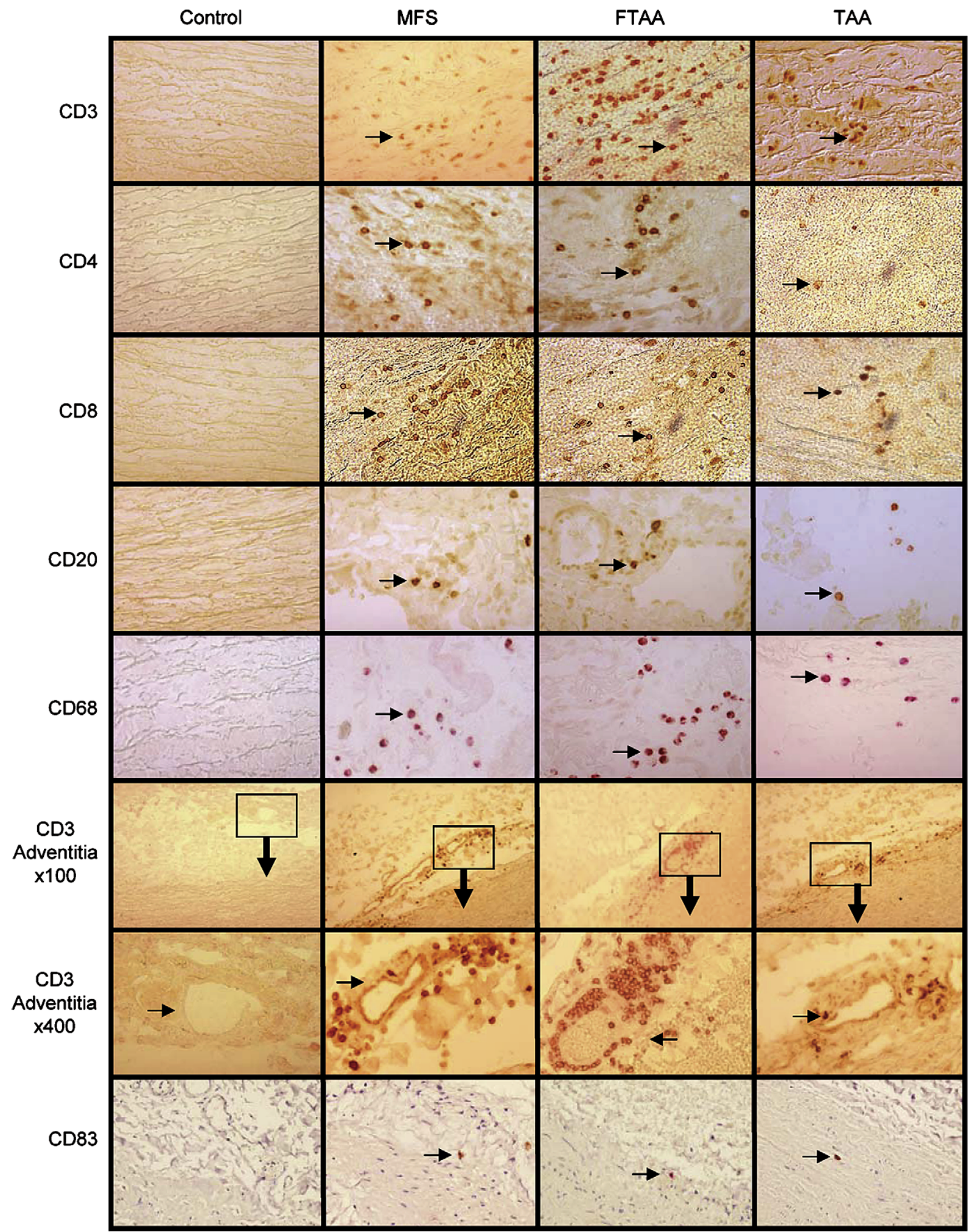


media and adventitia of the aortas from patients but were rarely found in control aortas (Figure 1, CD68 staining).

Quantization of the positive immune cells in the aortic media indicated that the patients with MFS, FTAA, and TAA had significantly increased amounts of $\mathrm{CD} 3+, \mathrm{CD} 4+$, $\mathrm{CD} 8+, \mathrm{CD} 68+$, and CD20+ cells when compared with control aortas $(P<.01)$ (Figure 2). Furthermore, the number of $\mathrm{CD} 3+$ cells in aortas of patients with MFS and CD68 + cells in aortas of patients with MFS and FTAA were also significantly increased when compared with those with sporadic aneurysms $(P<.01)$. $\mathrm{T}$ cells were the predominant inflammatory cell in the media, followed by macrophages. However, there was no significant difference in degrees of aortic enlargement among the 3 aneurysm groups $(P=$ .661 ), suggesting that the increased numbers of immune cells in the MFS and FTAA compared with sporadic TAA were not due to aortic expansion.

These studies also revealed a large number of inflammatory cells present in the adventitia, especially surrounding the vasa vasorum (Figure 1, CD3 staining in adventitia). Although both CD3 + and CD68 + cells were found in the adventitia, the cells surrounding the vasa vasorum were predominantly CD3 + (Figure 1, CD3, in adventitia). Infiltration of inflammatory cells in the adventitia was found to a lesser degree in sporadic TAA aortas compared with those of MFS and FTAA aortas, and not found in control aortas. Immunohistochemistry performed using antibodies directed against ICAM-1 and VCAM-1 showed that staining for ICAM-1 and VCAM-1 was increased around the vasa vasorum in the patients with FTAA and MFS compared with control aortas (Figure 3).

We sought to determine whether the number of inflammatory cells present in the aortic media at the time of surgery correlated with the patients' age at the time of prophylactic repair. These results demonstrated that both the number of $\mathrm{T}$ lymphocytes and macrophages in the aortic media were inversely related to the age of patients at the time of surgery $(r=-0.71, P=.002 ; r=-0.69, P=.002$, respectively $)$ (Figure 4). In contrast, there was no correlation between the diameter of the aortic aneurysm at the time of surgical repair and the number of CD3 + and CD68+ cells $(r=-0.2045$, $P=.447 ; r=-0.1917, P=.477$, respectively).

\section{Characterization of T-cell Receptors in T \\ Lymphocytes in Aortic Media}

To further characterize the genetic properties of the $\mathrm{T}$ cells in the aortic wall, RNA was extracted from the aortic tissues and used to assess the T-cell receptors. Real-time quantitative PCR assay for RNA expression demonstrated restricted use of the TCR BV gene in T cells derived from diseased aortas. A series of real-time PCR analyses revealed overexpression of BV22 and BV25 in more than a majority of the aortic specimens from patients with TAA (10/14 subjects) with 1 TCR $\mathrm{BV}$ gene contributing to more than $20 \%$ of the total use
(Figure E1). Overexpression of 1 gene was present in 5 samples for BV22 and 8 samples for BV25. The combination of the expression level of BV22 and BV25 contributed to more than $50 \%$ of the whole TCRBV gene use in 7 specimens. In contrast, BV gene distribution appeared highly heterogeneous in the remainder of aneurysm aortas (3/14) and control aortas. BV gene distribution also appeared highly heterogeneous in the paired peripheral blood mononuclear cells obtained from patients with MFS and TAA.

Clonality of the overexpressed BV22 and BV25 of T cells derived from selected aortic specimens by TCRBJ gene use was also examined. The TCRBJ profile of BV22 and BV25 was analyzed by using BV22 or BV25 forward primers and reverse primers for $13 \mathrm{BJ}$ genes with real-time PCR. Both BV22 and BV25 genes exhibited heterogeneous TCRBJ gene profiles in aortic specimens derived from controls and patients with TAA. These analyses revealed that no BJ genes were preferentially used in the context of the overexpressed BV22 and BV25 (data not shown).

The clonality of the T-cell receptors suggested that the $\mathrm{T}$ lymphocytes may be replicating in response to specific antigens presented by activated dendritic cells. Staining of the aneurysm aortas with a marker of activated dendritic cells, CD83, showed rare CD83 + cells located at the adventitial/ medial border, whereas CD83 + cells were not found in control aortas (Figure 1, CD83).

\section{Discussion}

An inflammatory component in MD, composed primarily of $\mathrm{T}$ cells and macrophages, was identified in TAAs resulting from single gene disorders, MFS, and familial TAA, and nongenetic, sporadic cases of TAA. More inflammatory cells were present in the aortas of patients with single gene defects than in patients with sporadic TAAs. The T-cell-associated vasculitis of the vasa vasorum and the increased expression of leukocyte adhesion molecules by the endothelial cells of the vasa vasorum suggest that a pathway for T-cell migration into the media is from the adventitia. The number of both inflammatory $\mathrm{T}$ lymphocytes and macrophages in the aortic media negatively correlated with patients' age at referral for prophylactic surgical repair, thus raising the possibility that the inflammatory infiltrate may contribute to disease progression. Alternatively, the inflammatory infiltrate could correlate with the aortic dilatation and corresponding pathologic changes, but not contribute to the disease progression. In contrast, there was no correlation between the size of the aorta and the number of inflammatory cells, implying that the inflammatory infiltrate did not simply result from irritation of the tissues from the progressive enlargement of the aorta. It is interesting to note that recent studies have suggested that dysregulation in TGF- $\beta$ signaling contributes to aortic disease in both MFS and familial TAA caused by TGFBR2 mutations. ${ }^{19,20}$ TGF- $\beta$ signaling plays a critical role in controlling $\mathrm{T}$-cell homeostasis and is required to prevent 


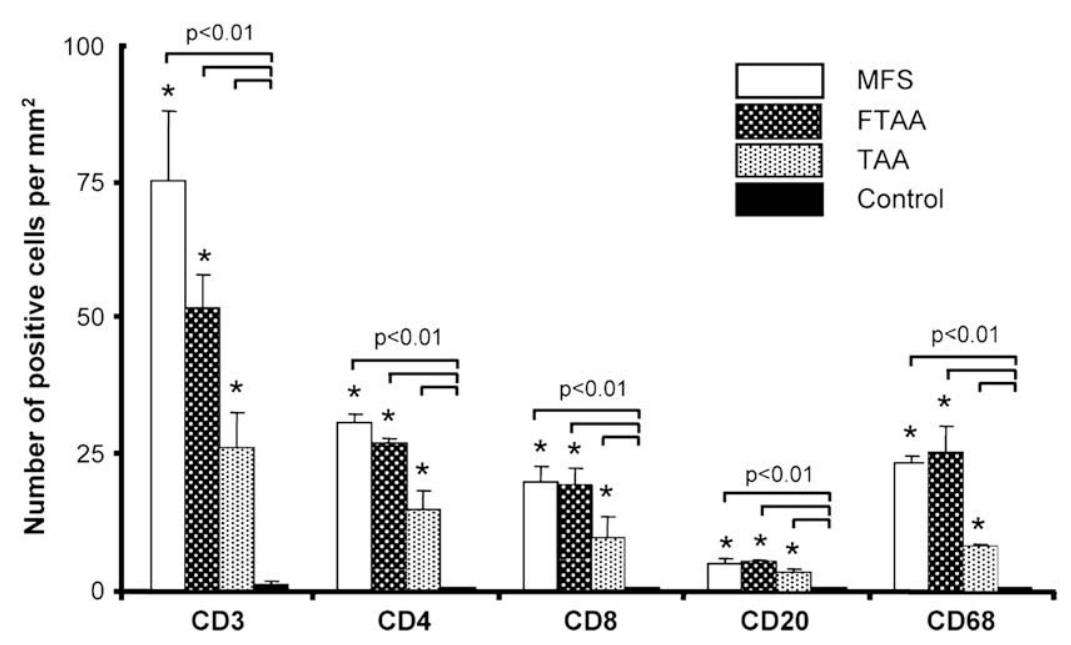

Figure 2. Morphometric quantization of lymphocytes, subpopulations of $T$ cells, and macrophages in ascending aortas of controls and patients with MFS, FTAA, and TAA. After immunohistochemistry of aortic tissue, CD3, CD4, CD8, CD20, and CD68-positive cells in the media in 10 contiguous high-power fields (magnification $400 \times$ ) were counted by 2 independent observers. In the aortas of patients with MFS, FTAA, and TAA, there was a significant increase in the number of CD3,+ CD4,+ CD8,+ CD20 + , and CD68+ cells when compared with control aortas $\left(^{*} P<.01\right)$. MFS, Marfan syndrome; FTAA, familial thoracic aortic aneurysm; $T A A$, thoracic aortic aneurysm.

undesirable self-targeted responses, suggesting that TGF$\beta$ dysregulation may contribute to the aortic T-cell immune response. $^{21}$

Tang and colleagues ${ }^{16}$ also observed that leukocyte infiltration increased in the media of aortas with TAAs compared with control aortas. They suggested dividing TAAs into 2 subgroups, bland and infiltrated aneurysms, on the basis of whether leukocytes infiltrate into the inner half of aortic media. T and B lymphocytes were significantly increased in the aortas with infiltrated aneurysms compared with those of bland aneurysms and controls. Macrophages were significantly increased in the aortic media with infiltrated aneurysms compared with those of bland aneurysms and controls. Although insufficient information is provided to determine the clinical cause of infiltrated and bland TAAs, it may be that the infiltrative aneurysms came from patients with a genetic cause to their aneurysms and the bland aneurysms were from patients with sporadic TAAs.

There are similarities between the characteristics of the inflammatory infiltrate present in TAAs and the inflammatory infiltrate described in giant-cell arteritis and Takayasu's arteritis. These disorders demonstrate a similar cellular immune response involving T cells, primarily CD4+ cells and macrophages, without evidence of an autoantibody component contributing to the pathology. ${ }^{22}$ Histology studies indicate that $\mathrm{T}$ cells enter tissue with activation of endothelial cells in the vasa vasorum and not through the intimal endothelium. Furthermore, a limited T-cell receptor repertoire has been shown to infiltrate the aortic tissue in Takayasu's arteritis, suggesting that an aortic tissue antigen presented in the cleft of certain major histocompatibility complex molecules in the aortic tissue was targeted by the T cells. ${ }^{23}$ Restricted use of T-cell receptors on the $\mathrm{T}$ cells was also identified in TAAs, specifically TCRBV18, TCRBV22, and TCRBV25. Although the direct link between dendritic cell function and T-cell activation remains unclear in the TAA tissue, the presence of activated dendritic cells capable of presenting antigen in the adventitia of TAAs but not in the control aortas provides further support that a tissue antigen is targeted by the T cells.

Once activated, CD4 $+\mathrm{T}$ cells can polarize into T-helper type I (Th1) or 2 (Th2) cells, which in turn control the inflammatory cascades in different diseases. A recent study of transmural inflammation of TAAs indicated that the Th1-type or proinflammatory process is the dominant immune response

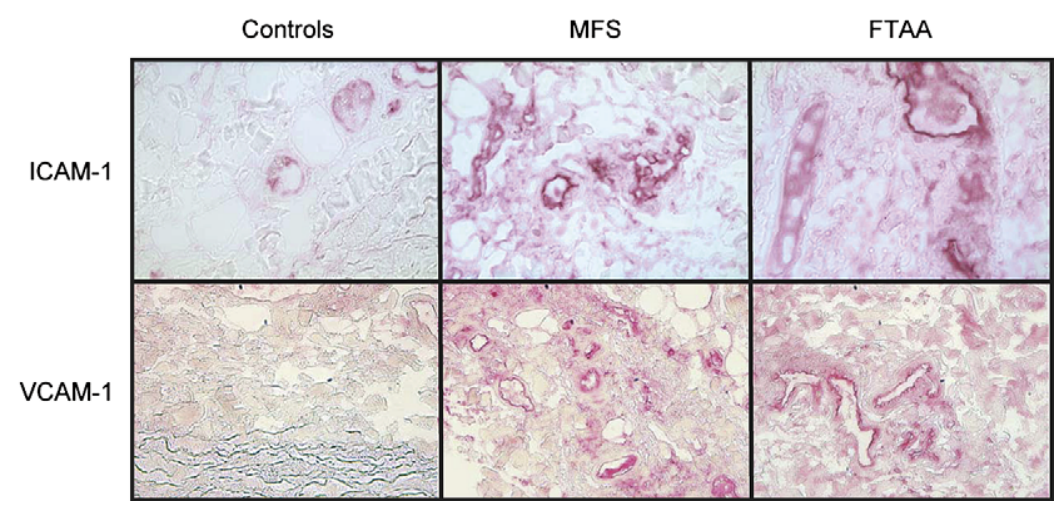

Figure 3. Increased expression of leukocyte adhesion molecules, ICAM-1, and VCAM-1 in the vasa vasorum in the adventitia of patients with MFS and FTAA. Immunohistochemistry revealed positive immunostaining for ICAM-1 and VCAM1 in the vasa vasorum from patients with MFS and FTAA. Magnification $400 \times$. MFS, Marfan syndrome; FTAA, familial thoracic aortic aneurysm; ICAM, intercellular adhesion molecule; VCAM, vascular cell adhesion molecule. 

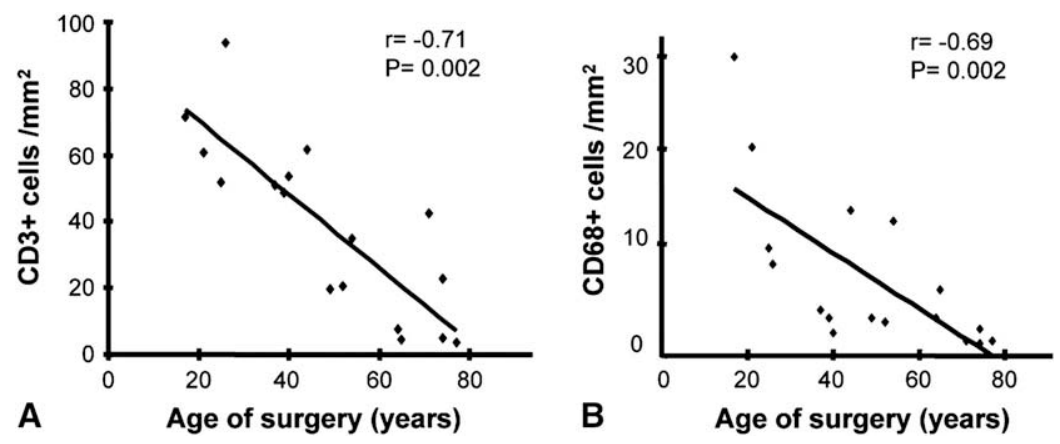

Figure 4. Inverse correlation between the age of patients at the time of prophylactic repair of the aorta and the number of $T$ lymphocytes (CD3+ staining) and macrophages (CD68 + staining) in the aortic media of patients. CD3 + cells $(A)$ and CD68 + cells $(B)$ were counted in 10 contiguous high-power fields of the aortic media of TAAs from 19 patients with MFS, FTAA, and sporadic TAA.

occurring in aneurysms. The up-regulation of interferongamma significantly correlated with both outward vascular remodeling and intimal expansion of TAAs. ${ }^{16}$ Th1 responses favor effective clearance of intracellular pathogens and play crucial roles in the pathophysiology of organ-specific autoimmune diseases. Autoimmune encephalomyelitis ${ }^{24}$ and thyroiditis $^{25}$ are two good examples that autoimmune diseases are initiated by Th1-mediated responses. The prominent autoimmune cause of multiple sclerosis is also considered to be the aberrant activation of interferon-gamma-producing Th1 cells that recognize self-peptides of the myelin sheath. The restricted uses of TCRBV and infiltration of predominant Th1-type cells in TAA lesions suggest that a Th1-mediated proinflammatory response could be a mechanism that contributes to the pathogenesis of TAA.

The results of our study parallel the results of a novel mouse model of TAAs, the interleukin-1 receptor antagonist deficient mouse (interleukin-1-Ra-/-). ${ }^{26}$ An inflammatory aortitis of the ascending aorta develops in the deficient mice that is not present in wild-type mice, involving the medial infiltration of T lymphocytes and macrophages. Furthermore, peripheral $\mathrm{T}$ cells from the interleukin-1-Ra-/- mouse cause aortic aneurysms in nu/nu mice, suggesting that activated or memory $T$ cells are generated and involved in the development of the ascending aortic disease. As in giant cell and Takayasu's arteritis, the pathogenic antigens in the aorta in this mouse model require further investigation.

In our study, no preferential use of BJ gene was selected in the context of overexpressed BV22 and BV25 in the majority of TAA aortas, leading to an alternative possibility that a superantigen-driven stimulation of $\mathrm{V} \beta 22$ and $\mathrm{V} \beta 25$-positive $\mathrm{T}$ cells in the aortic tissues of patients with TAA may be one of the major mechanisms contributing to the initial immune response in the aortic tissue. Mitogens, superantigens, and nominal antigens use distinct mechanisms to activate $\mathrm{T}$ cells and induce proliferation. Mitogens and nominal antigens induce a polyclonal proliferation of $\mathrm{T}$ cells independently of the TCRBV family expressed. In contrast, stimulation of certain superantigens, such as toxic shock syndrome toxin-1, is based on the TCR BV family and independent of complementary determining region 3 sequence. The
T-cell response to superantigens is oligoclonal and restricted in terms of complementary determining region 3 .

The phenotype and biological activity of invading $\mathrm{T}$ cells and macrophages in TAAs should be further characterized before drawing conclusions on their relevance to the disease process. The limited access to aortic tissue in humans impedes assessing the role of the inflammatory infiltrate in disease progression. Despite these limitations, our study results suggest that an immune-mediated aortitis may contribute to the pathogenesis of TAAs and that a spectrum of aortic disease processes from Takayasu's arteritis to TAA formation involve inflammatory infiltrates in the aortic media. Further investigations are needed to verify the role of this inflammatory infiltrate in the progressive molecular pathology of TAAs.

The authors are grateful to the patient and their physicians involved in this study and to Dr Craig T. Bason for referring a patient for this study.

\section{References}

1. Erdheim J. Medionecrosis aortae idiopathica cystica. Virchows Arch Path Anat. 1930;276:187.

2. Milewicz DM, Dietz HC, Miller DC. Treatment of aortic disease in patients with Marfan syndrome. Circulation. 2005;111:e150-7.

3. Dietz HC, Pyeritz RE. Mutations in the human gene for fibrillin-1 (FBN1) in the Marfan syndrome and related disorders. Hum Mol Genet. 1995;4. Spec No:1799-809.

4. Pereira L, Andrikopoulos K, Tian J, Lee SY, Keene DR, Ono R, et al. Targeting of the gene encoding fibrillin-1 recapitulates the vascular aspect of Marfan syndrome. Nat Genet. 1997;17:218-22.

5. Mizuguchi T, Collod-Beroud G, Akiyama T, Abifadel M, Harada N, Morisaki T, et al. Heterozygous TGFBR2 mutations in Marfan syndrome. Nat Genet. 2004;36:855-60.

6. Nicod P, Bloor C, Godfrey M, Hollister D, Pyeritz RE, Dittrich H, et al. Familial aortic dissecting aneurysm. J Am Coll Cardiol. 1989;13:811-9.

7. Milewicz DM, Chen H, Park ES, Petty EM, Zaghi H, Shashidhar G, et al. Reduced penetrance and variable expressivity of familial thoracic aortic aneurysms/dissections. Am J Cardiol. 1998;82:474-9.

8. Guo D, Hasham S, Kuang SQ, Vaughan CJ, Boerwinkle E, Chen H, et al. Familial thoracic aortic aneurysms and dissections: genetic heterogeneity with a major locus mapping to 5q13-14. Circulation. 2001;103: 2461-8.

9. Hasham SN, Willing MC, Guo DC, Muilenburg A, He RM, Tran VT, et al. Mapping a locus for familial thoracic aortic aneurysms and dissections (TAAD2) to 3p24-25. Circulation. 2003;107:3184-90. 
10. Guo DC, Pannu H, Tran-Fadulu V, Papke CL, Yu RK, Avidan N, et al. Mutations in smooth muscle alpha-actin (ACTA2) lead to thoracic aortic aneurysms and dissections. Nat Genet. 2007;39:1488-93.

11. Vaughan CJ, Casey M, He J, Veugelers M, Henderson K, Guo D, et al. Identification of a chromosome 11q23.2-q24 locus for familial aortic aneurysm disease, a genetically heterogeneous disorder. Circulation. 2001;103:2469-75.

12. Van Kien PK, Mathieu F, Zhu L, Lalande A, Betard C, Lathrop M, et al. Mapping of familial thoracic aortic aneurysm/dissection with patent ductus arteriosus to 16p12.2-p13.13. Circulation. 2005;112:200-6.

13. Loeys BL, Schwarze U, Holm T, Callewaert BL, Thomas GH, Pannu H, et al. Aneurysm syndromes caused by mutations in the TGF-beta receptor. N Engl J Med. 2006;355:788-98.

14. Pannu H, Fadulu V, Chang J, Lafont A, Hasham SN, Sparks E, et al. Mutations in transforming growth factor-beta receptor type II cause familial thoracic aortic aneurysms and dissections. Circulation. 2005;112:513-20.

15. He R, Guo DC, Estrera AL, Safi HJ, Huynh TT, Yin Z, et al. Characterization of the inflammatory and apoptotic cells in the aortas of patients with ascending thoracic aortic aneurysms and dissections. J Thorac Cardiovasc Surg. 2006;131:671-8.

16. Tang PC, Yakimov AO, Teesdale MA, Coady MA, Dardik A, Elefteriades JA, et al. Transmural inflammation by interferon-gammaproducing $\mathrm{T}$ cells correlates with outward vascular remodeling and intimal expansion of ascending thoracic aortic aneurysms. FASEB J. 2005; 19:1528-30.

17. Sun W, Popat U, Hutton G, Zang YC, Krance R, Carrum G, et al. Characteristics of $\mathrm{T}$-cell receptor repertoire and myelin-reactive $\mathrm{T}$ cells reconstituted from autologous haematopoietic stem-cell grafts in multiple sclerosis. Brain. 2004;127:996-1008.
18. Puisieux I, Even J, Pannetier C, Jotereau F, Favrot M, Kourilsky P. Oligoclonality of tumor-infiltrating lymphocytes from human melanomas. $J$ Immunol. 1994;153:2807-18.

19. Neptune ER, Frischmeyer PA, Arking DE, Myers L, Bunton TE, Gayraud B, et al. Dysregulation of TGF-beta activation contributes to pathogenesis in Marfan syndrome. Nat Genet. 2003;33:407-11.

20. Habashi JP, Judge DP, Holm TM, Cohn RD, Loeys BL, Cooper TK, et al. Losartan, an AT1 antagonist, prevents aortic aneurysm in a mouse model of Marfan syndrome. Science. 2006;312:117-21.

21. Gorelik L, Flavell RA. Transforming growth factor-beta in T-cell biology. Nat Rev Immunol. 2002;2:46-53.

22. Weyand CM, Goronzy JJ. Medium- and large-vessel vasculitis. $N$ Engl J Med. 2003;349:160-9.

23. Seko Y, Sato O, Takagi A, Tada Y, Matsuo H, Yagita H, et al. Restricted usage of T-cell receptor Valpha-Vbeta genes in infiltrating cells in aortic tissue of patients with Takayasu's arteritis. Circulation. 1996;93: 1788-90.

24. Behi ME, Dubucquoi S, Lefranc D, Zephir H, De Seze J, Vermersch P, et al. New insights into cell responses involved in experimental autoimmune encephalomyelitis and multiple sclerosis. Immunol Lett. 2005;96: 11-26.

25. Kimura H, Tzou SC, Rocchi R, Kimura M, Suzuki K, Parlow AF, et al. Interleukin (IL)-12-driven primary hypothyroidism: the contrasting roles of two Th1 cytokines (IL-12 and interferon-gamma). Endocrinology. 2005;146:3642-51.

26. Shepherd J, Nicklin MJ. Elastic-vessel arteritis in interleukin-1 receptor antagonist-deficient mice involves effector Th1 cells and requires interleukin-1 receptor. Circulation. 2005;111:3135-40. 

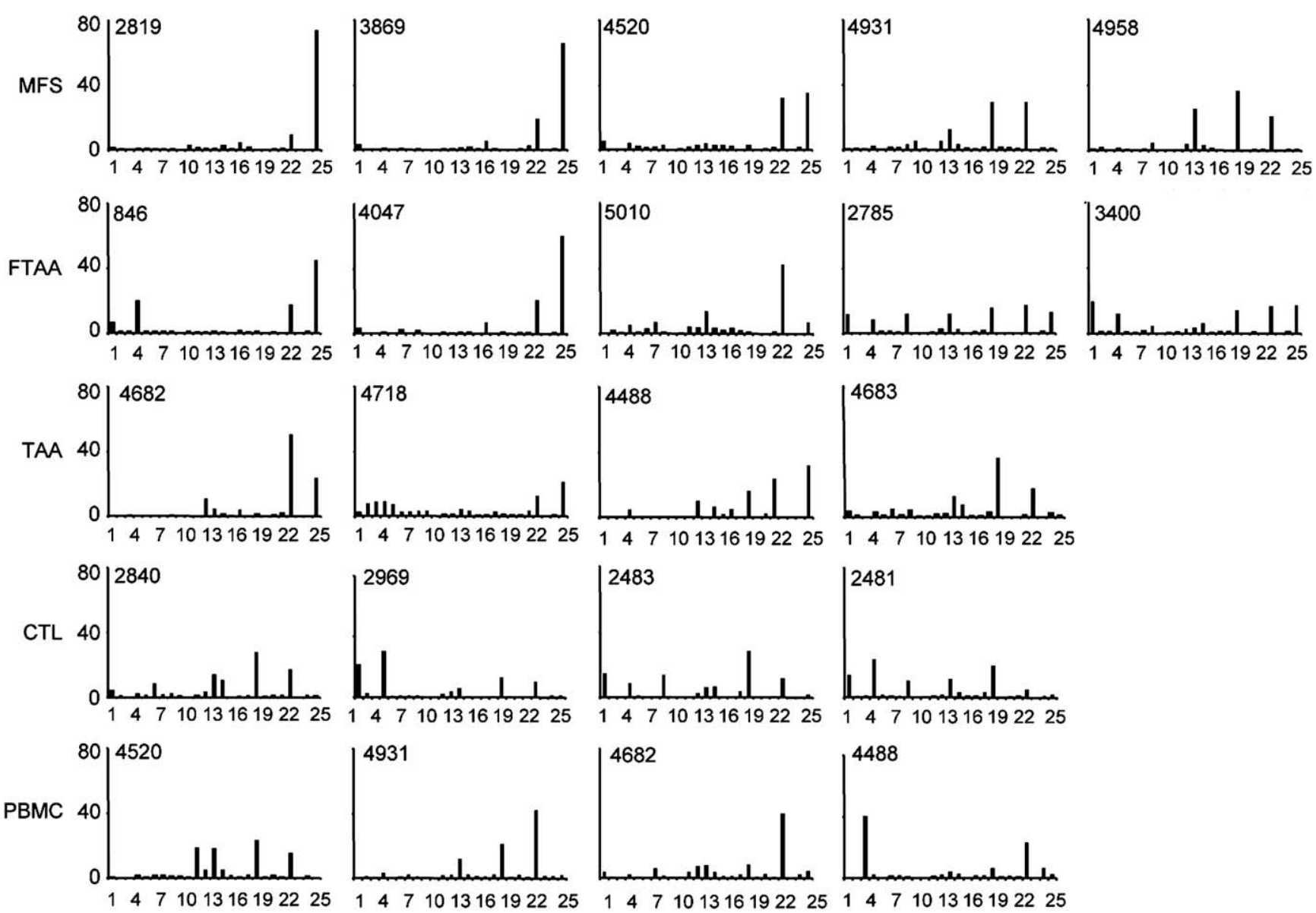

Figure E1. TCR BV gene distribution profiles in the aortas of controls and patients with MFS, FTAA, TAA, and sporadic TAA, and in peripheral blood mononuclear cells of patients with MFS and TAA. TCR BV gene expression was analyzed quantitatively using RNA from aortic tissue and peripheral blood mononuclear cells by real-time PCR using specific primers for $25 \mathrm{BV}$ genes. BV gene distribution is presented as the mean percentage expression of each BV gene relative to $\mathrm{BC}$ expression on the y axis. MFS, Marfan syndrome; FTAA, familial thoracic aortic aneurysm; TAA, thoracic aortic aneurysm; CTL, control; PBMC, peripheral blood mononuclear cell. 